\title{
Studies on the Properties of Rice-Husk-Filled-PP Composites - Effect of Maleated PP
}

\author{
Simone Maria Leal Rosa ${ }^{\mathrm{a}}$,Evelise Fonseca Santos ${ }^{\mathrm{b}}$, \\ Carlos Arthur Ferreira, Sônia Marlí Bohrz Nachtigallb* \\ ${ }^{a}$ Escola de Engenharia, \\ Universidade Federal do Rio Grande do Sul - UFRGS \\ 91501-930, PO Box 15010, Porto Alegre - RS, Brazil \\ ${ }^{\mathrm{b}}$ Instituto de Química, \\ Universidade Federal do Rio Grande do Sul - UFRGS, \\ Av. Bento Gonçalves 91501-970, 9500, Porto Alegre - RS, Brazil
}

Received: February 6, 2009; Revised: May 6, 2009

\begin{abstract}
Rice husk is a by-product of rice milling process that usually finds inadequate final disposal (burning, land filling). Thermoplastics composites filled with rice husk flour are materials that offer an alternative for using this agricultural resource viewing the production of low dense materials with some specific properties. In this work composites of polypropylene (PP) and rice husk flour (RHF) were prepared by melt extrusion. Maleic anhydridemodified PP (MAPP) was added as a coupling agent. It was verified that tensile strength decreased with filler loading. The presence of MAPP improved this property showing a strong dependence on the MAPP/RHF ratio (MAPP/RHF $=0.03$ produced the best results). The density of the composites slightly increased with filler and coupling agent in comparison to pure PP. The presence of MAPP diminished more than $20 \%$ water uptake in highly-loaded composites.
\end{abstract}

Keywords: polymer-matrix composites, density, coupling agent, wettability

\section{Introduction}

Recent interest on the environmental impact of polymer-based materials has lead to the development of new products prepared with recycled polymers and/or containing biodegradable materials. Lignocellulosic plastic composites constitute an important set within this kind of materials showing several advantages over traditional mineral-filled plastic composites: low density, low production costs, biodegradability, renewability, etc. Stiffness, hardness and dimensional stability of plastics have also been improved by incorporation of lignocellulosic fillers ${ }^{1,2}$.

However, the use of agro-fibers shows some drawbacks such as degradation at relatively low temperature due to the presence of cellulose and hemicellulose. This early thermal degradation limits the allowed processing temperature to less than $200{ }^{\circ} \mathrm{C}$ and restricts the type of thermoplastics that can be used with agro-fibres to some commodity plastics such as PE, PP, PVC and PS ${ }^{[3]}$. Natural fiber/PP composites have been used in automotive applications and recently they have been investigated for using in construction, such as building profiles, decking, railing products, etc. ${ }^{1,4}$.

Other factors should be taken into account when designing composites made of lignocellulosic fibers for specific applications, among them its poor resistance to moisture ${ }^{5}$. Outdoor applications have raised the interest on this property since moisture absorbed by the composite led to dimensional changes and to decreasing mechanical performance ${ }^{4}$. These negative effects can be reduced if the fibers are encapsulated in the plastic with good adhesion between the fibers and the matrix. The addition of a compatibilizer has been a useful tool for achieving such adhesion. Maleic anhydride-grafted PP (MAPP) is the most common compatibilizer used to improve interfacial adhesion for bio-fillers/apolar thermoplastic matrices even so new alternatives are being currently studied ${ }^{6,7}$.

Rice husk $(\mathrm{RH})$ is one of the major agricultural residues produced as a by-product during rice processing. Usually it has been a problem for rice farmers due to its resistance to decomposition in the ground, difficult digestion and low nutritional value for animals ${ }^{8}$. According to Marti-Ferrer the lignin and hemicellulose contents of rice husk are lower than wood whereas the cellulose content is similar. For this reason RHF can be processed at higher temperatures than wood. Therefore, the use of rice husk in the manufacture of polymer composites is attracting much attention.

The group of Kim, in Korea, has published many studies dealing with PP-rice husk composites ${ }^{9-14}$. They observed that tensile and impact strengths (notched and unnotched specimens) decreased with increasing filler loading while the elastic modulus increased ${ }^{9,11}$. The thickness swelling and the absorption of water were shown to slightly increase as the filler loading increased, but this was to a negligible extent as compared with wood-based composites. Despite the low properties of the composites the researchers concluded that rice husk flour could be utilized as a biodegradable filler to minimize environmental pollution ${ }^{9}$. Addition of PPMA as coupling agent improved the water absorption properties ${ }^{10}$. In other studies the researchers verified 
improvements in thermal stability, dynamic mechanical properties, tensile properties and crystallinity with addition of MAPP ${ }^{12-14}$.

A recent study of our group showed similar results, that means, higher storage modulus and higher crystallinity for rice-husk filled PP. Addition of MAPP enhanced thermal and mechanical properties ${ }^{15}$.

The effect of four different coupling agents on the properties of RHF-filled block copolymer PP was studied ${ }^{16}$. The composite treated with MAPP showed the highest storage modulus.

Sain and coworkers ${ }^{17}$ introduced the percolation theory for explaining the moisture absorption behaviour of RHF/HDPE composites. According to the researchers at high fiber loading (when accessible fiber ratio is high) the diffusion process is the dominant mechanism while at low fiber loading percolation is the dominant mechanism.

Despite of the great interest on lightweight materials few studies have focused on determining the density of natural fibers-filled polymer composites. In the present study we used a thermoplastic polymer as matrix (PP) and rice husk flour (RHF) as filler to prepare composites. PP modified with maleic anhydride (MAPP) was used as coupling agent. The objective of the work was to explore the effect of RHF loading and the presence of MAPP on the density, mechanical properties and water absorption behavior of the composites.

\section{Experimental Procedures}

\subsection{Materials}

Isotactic PP was supplied by BRASKEM ${ }^{\circledR}$ (Triunfo, Brazil) in the form of pellets with a density of $0.91 \mathrm{~g} / \mathrm{cm}^{3}$ and a melt flow index of $3.5 \mathrm{~g} / 10 \mathrm{~min}\left(230{ }^{\circ} \mathrm{C} / 2160 \mathrm{~g}\right)$. Rice husk was supplied by Engenho Meirebe (Eldorado do Sul, Brazil). MAPP was obtained from Crompton-Uniroyal Chemical Corporation ${ }^{\circledR}$ (Naugatauk, USA), in the form of Polybond-3200TM.

\subsection{Preparation of the composites and samples}

Rice husk was previously ground and screened. The particle sizes of RHF used were from 16 to 150 mesh. The filler was oven dried at $80{ }^{\circ} \mathrm{C}$, for 24 hours, at $30 \mathrm{~mm} \mathrm{Hg}$, to adjust its moisture contents and then it was stored over a desiccant. The RHF was used without any subsequent treatment.

A laboratory-size conical co-rotatory twin-screw extruder Haake, Model Rheomex CTW 100p, was employed for compounding RHF and PP. The screw speed was $40 \mathrm{rpm}$ and the temperature range varied from 170 to $190{ }^{\circ} \mathrm{C}$. 4 levels of filler loading $(10,20,30$ and $40 \mathrm{wt}$. (\%)) were used. After pelletizing the composites were compression moulded. The hot press procedure involved preheating at $190{ }^{\circ} \mathrm{C}$ for 10 minutes followed by compressing at $2.5 \mathrm{KPa}$ for 4 minutes at the same temperature. After this the set was allowed to cool down to room temperature and the samples were manually removed from the moulds.

\subsection{Mechanical testing}

Tensile tests were carried out according to ASTM D638 using samples obtained as described above. Tensile properties were measured at room temperature using an EMIC tensile tester with $5 \mathrm{kN}$ load cell, at $5 \mathrm{~mm} / \mathrm{min}$ crosshead speed.

\subsection{Water absorption study}

The water absorption tests were conducted according to ASTM D 1037-99. Water absorbed was determined by immersion of $1.8 \mathrm{~mm}$ thick sheet samples in distilled water at room temperature for 400 hours. The weight increase was periodically measured. The amount of water absorbed by the composites at room temperature was calculated according to the following equation:

$$
M_{t}(\%)=\frac{W_{t}-W_{0}}{W_{0}} \times 100
$$

where $M_{t}$ is the amount of water absorbed at time $t, w_{t}$ is the weight of the sample at time $t$ and $w_{0}$ is the initial weight of the sample.

\subsection{Density measurements}

The density of the composites was measured using a picnometer, at room temperature, using $\sim 5.0 \mathrm{mg}$ samples. Acetone was the liquid used for the measurement of the bulk density.

\subsection{SEM analysis}

The photomicrographs were obtained from cryogenic-fractured specimens. The test specimens were attached to an aluminum stub and sputtered with gold to eliminate the electron charging effects. A $\mathrm{JEOL}^{\circledR}$ microscope JSM 5800 operating at $20 \mathrm{kV}$ was used.

\section{Results}

The compositions of the systems are shown in Table 1. RHF loadings varied from 10 to $40 \mathrm{wt}$. (\%) while MAPP varied from 1.2 to 1.8 wt. (\%) (corresponding to 2 wt. (\%) of PP content for each sample).

\subsection{Tensile tests}

Mechanical properties are of major importance for all applications of natural-filled polymer composites. The tensile strengths of PP/RHF composites are shown in Figure 1. We observed that the tensile strength decreased with increasing filler loading. This behaviour has been described in similar studies and it has been explained by the increase of the interfacial area with filler loading ${ }^{8,18}$. Since the filler particles are very small a high interfacial surface exists between the polar filler and the apolar matrix. As this area increases the worsening bonding between them decreases the tensile strength. It has also been shown that for irregularly-shaped fillers the strength of the composites can decrease due to the inability of the filler to support stresses transferred from the polymer matrix ${ }^{19}$. On the other hand, poor interfacial bonding causes partially separated micro-spaces between the filler particles and the polymer matrix. The presence of voids obstructs stress propagation when tensile stress is loaded and induce increased brittleness ${ }^{9}$.

Easy agglomeration is a known characteristic of $\mathrm{RHF}^{10}$. The presence of agglomerates can generate flaws and create additional voids between the filler and the matrix polymer thus diminishing tensile strength.

Table 1. Formulation of the PP/RHF composites.

\begin{tabular}{ccccc}
\hline Sample & RHF wt. (\%) & PP wt. (\%) & MAPP wt. (\%) & MAPP/RHF \\
\hline 1 & 0.0 & 100.0 & 0.0 & 0.0 \\
2 & 10.0 & 90.0 & 0.0 & 0.0 \\
3 & 10.0 & 88.2 & 1.8 & 0.18 \\
4 & 20.0 & 80.0 & 0.0 & 0.0 \\
5 & 20.0 & 78.4 & 1.6 & 0.08 \\
6 & 30.0 & 70.0 & 0.0 & 0.0 \\
7 & 30.0 & 68.6 & 1.4 & 0.05 \\
8 & 40.0 & 60.0 & 0.0 & 0.0 \\
9 & 40.0 & 58.8 & 1.2 & 0.03 \\
\hline
\end{tabular}




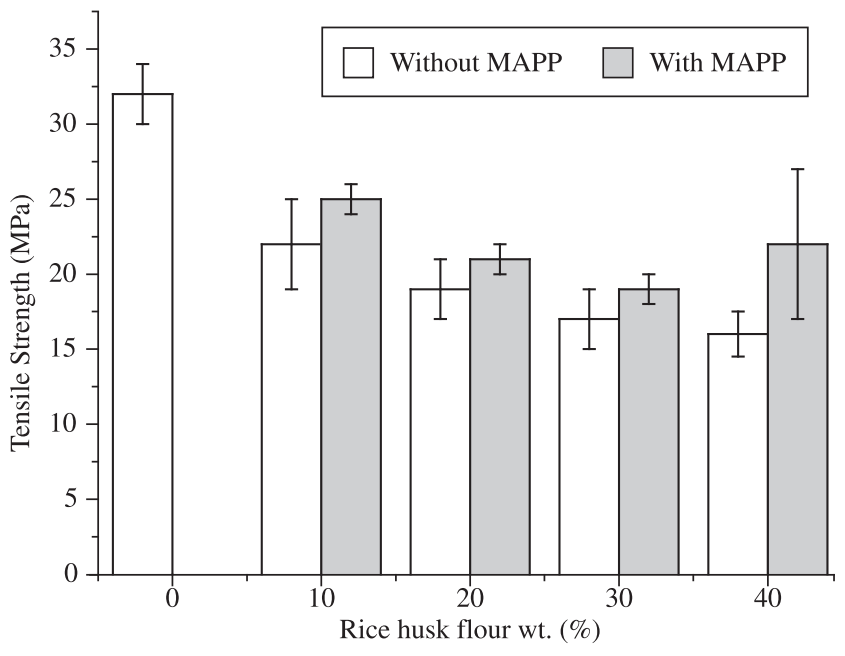

Figure 1. Effect of RHF and MAPP on tensile strength.

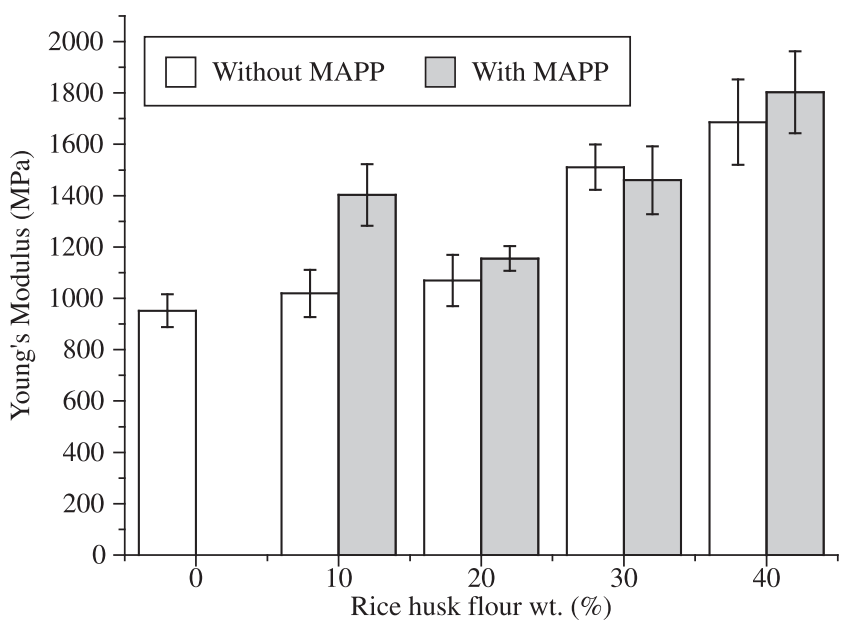

Figure 2. Effect of RHF and MAPP on Young's modulus.

It was found that the addition of $40 \mathrm{wt}$. (\%) RHF resulted in a decrease of approximately $50 \%$ in tensile strength values compared to pure PP. The maximum tensile strength determined for PP/RHF specimens prepared without the coupling agent was $22 \mathrm{MPa}$.

Figure 1 also shows the relationship between the tensile strength and the filler loading in the presence of the coupling agent. Addition of $2 \mathrm{wt}$. (\%)MAPP (with respect to the polymer content) showed to increase the tensile strength of the composites for all filler loads, indicating that it can be efficiently used as a coupling agent for these RHF/PP composites. This behavior can be attributed to the reaction of the hydrophilic $-\mathrm{OH}$ groups from the filler and the acid anhydride groups from MAPP, thus forming ester linkages, as it has been proposed in the literature ${ }^{11}$. The highest effect of MAPP was observed in the composite containing 40 wt. (\%) of filler, showing an improvement of $37 \%$ in tensile strength. In this sample the MAPP/RHF ratio was 0.03 , the lowest one in the set. According to studies of Pukansky ${ }^{20}$ coupling agent/filler ratios higher than 0.05 did not increase and even decreased tensile strength in PP/wood-flour composites. Our results are in accordance with these observations. One reason for this behavior can be the worsening properties of the coupling agent itself when present in high concentration.

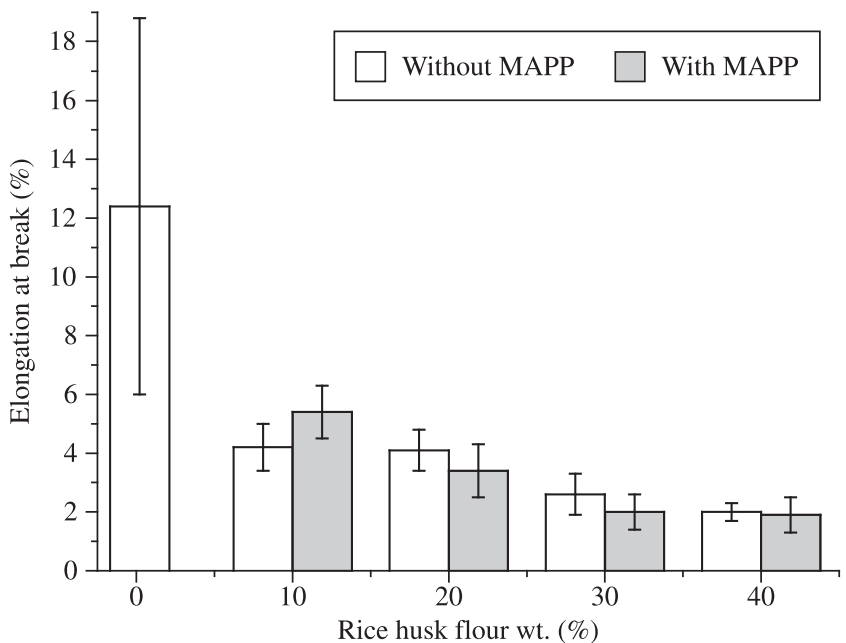

Figure 3. Effect of RHF and MAPP on elongation-at-break.

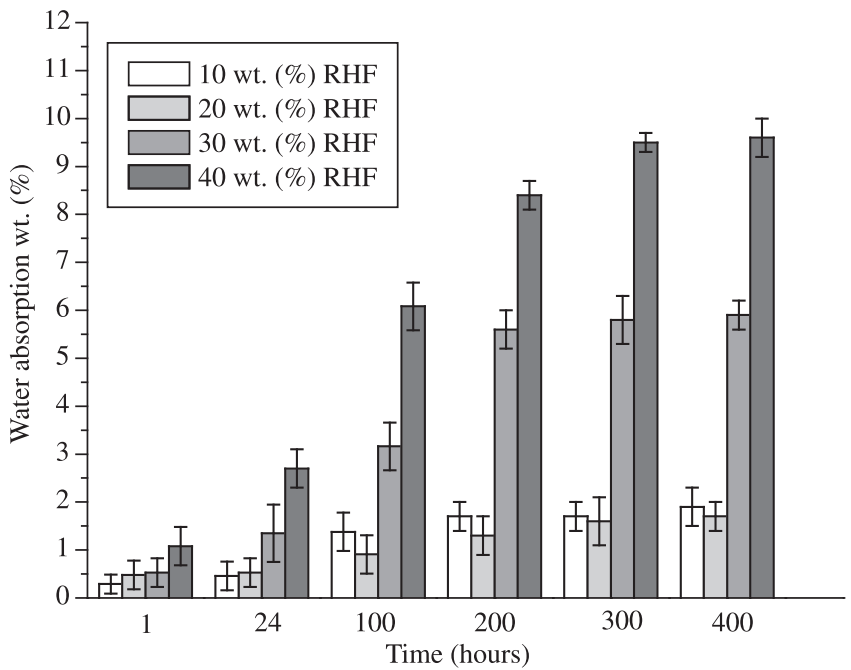

Figure 4. Water absorption at different RHF loadings.

Results obtained from tensile modulus determinations indicated that increasing filler loading showed a tendency to increase the composite stiffness, as it can be seen in Figure 2. It was verified that stiffness increased from $950 \mathrm{MPa}$ to more than $1800 \mathrm{MPa}$. This is a common behavior when rigid fillers are incorporated into softer polymer matrices. Natural lignocellulosic fillers have been found as having elastic modulus higher than $\mathrm{PP}^{[21]}$. Because of this the rigidity of its composites tends to strongly increase with addition of these fillers. Some authors have also related the increase in composites' rigidity with the reduction of polymer chains mobility in the presence of the filler ${ }^{22}$.

We observed that the presence of MAPP did not influence the tensile modulus for compositions containing from 20 to $40 \mathrm{wt}$. (\%) of filler. This result agrees with some literature sources that claim that the presence of maleated PP does not influence stiffness ${ }^{20,23}$. However, in the case of the composite containing $10 \mathrm{wt}$. (\%) RHF the effect of MAPP on the elastic modulus seemed to be significant. Despite a possible lack of homogeneity in the dispersion of the filler this result can also be related to some higher interaction among the coupling agent and the RHF since in this composition the $\mathrm{MAPP} / \mathrm{RHF}$ ratio was the highest one $(\mathrm{MAPP} / \mathrm{RHF}=0.18)$.

Incorporation of the filler resulted in an abrupt drop in elongation at break compared to the PP matrix (Figure 3). Elongation-at-break 
was seen to diminish with RHF concentration. The effect of the coupling agent was not evident on this property.

\subsection{Water absorption behavior}

Due to the high hydrophilic character of the components of natural fillers water absorption is a severe handicap for some applications of natural fiber polymer composites. Generally speaking, polypropylene hardly absorbs water due to its hydrophobic structure; however, rice husk can absorb water because of its hydrophilic character. In our study we investigated the relationship between the moisture absorption of the composites and the filler loadings. Results showed that increasing RHF concentration and increasing water contact time

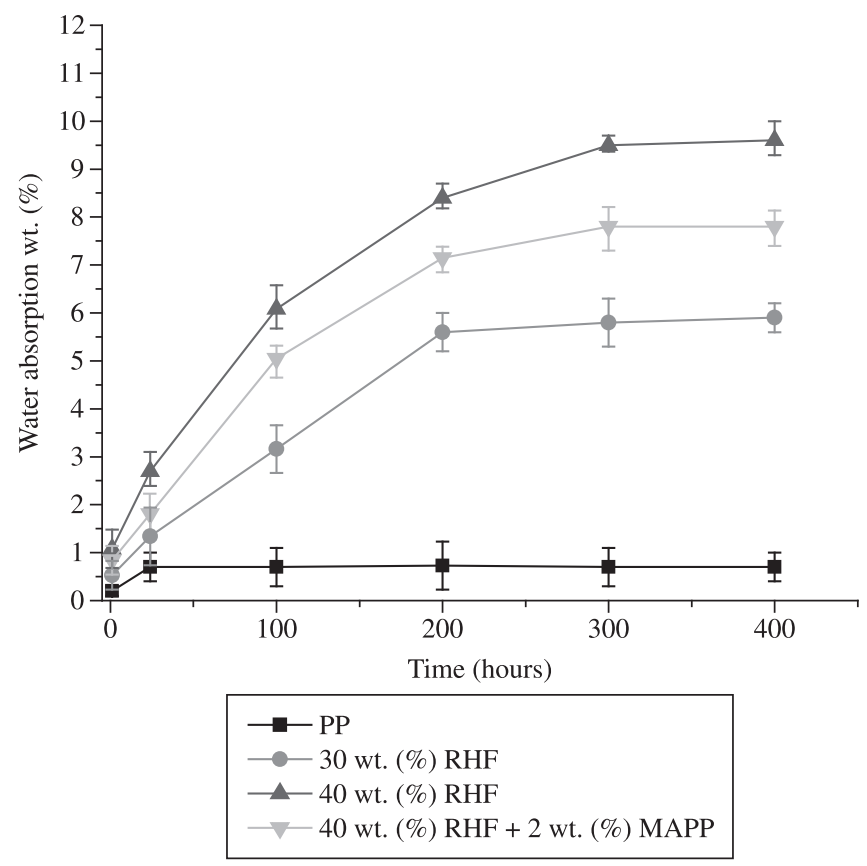

Figure 5. Water absorption in the presence of MAPP.

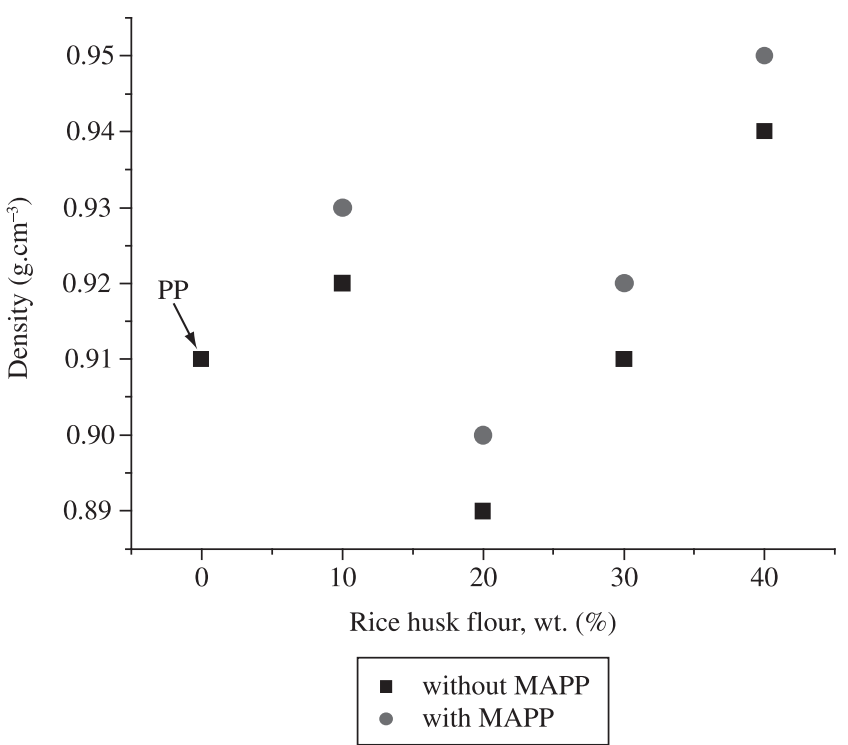

Figure 6. Density measurements of the materials. greatly increased water absorption, as it can be seen in Figure 4. PP homopolymer did not show any measurable water absorption and the behaviour of the composites containing 10 and $20 \mathrm{wt}$. (\%) RHF could not be distinguished since they showed low levels of water absorption. Prachayawarakorn et al. ${ }^{24}$ proposed that rice husk-filled-polypropylene composites could absorb water by three different boundaries, i.e. at the lumen and cell wall of rice husk and at the voids created in the interfacial area between the filler and PP. Results of water absorption for the low RHF-containing composites (10 and 20 wt. (\%) RHF) indicate that the presence of voids and spaces plays an important role in the degree of water absorption since similar water levels were uptaken by these samples despite of the different hydrophilic compositions. Composites containing 30 and $40 \mathrm{wt}$. (\%) RHF showed the expected behavior of higher level of water absorption attained by the composite with the highest concentration of the hydrophilic filler. This suggests that water penetration into the filler voids can be the more important mechanism of water uptaking as the RHF level increased in composites. It was verified that the composite containing $40 \mathrm{wt}$. (\%) RHF showed about $11 \mathrm{wt}$. (\%) of water absorption after 400 hours of exposition to water. PP absorbed only $0.7 \mathrm{wt}$. (\%) water within this time of exposure. Such bad behavior can severely affect the properties of the composites mainly in outdoor applications.

The addition of the coupling agent MAPP decreased water absorption, as it was expected. The behavior is illustrated in Figure 5. A decrease of more than $20 \%$ in water absorption was verified for composites containing 40 wt. (\%) RHF after 400 hours of water exposition. It can be proposed that the chemical reaction between the coupling agent and the filler reduced the number of available hydrophilic groups. Apart from this the formation of an interfacial layer over the surface of the dispersed particles could prevent water from penetrating its interior.

\subsection{Density determinations}

Natural lignocellulosic materials have attracted the attention of scientists and engineers for using as fillers in polymer composites due to its low densities as compared to traditional mineral fillers (glass fibers, calcium carbonate, etc). In solid-like composites the density of natural fibers (that is usually between 1.1-1.5 g.cm ${ }^{-3}$ ) is a key for determining the density of the composites ${ }^{25}$.

The bulk density of RHF was determined using a picnometer and acetone. The value obtained for RHF was $1.3 \mathrm{~g} . \mathrm{cm}^{-3}$. As the polymer matrix shows lower density $\left(0.91 \mathrm{~g} . \mathrm{cm}^{-3}\right)$ it was supposed that the densities of the composites would be higher than that of PP homopolymer. However it could be verified that the final density did not strictly follow the rule of mixtures, since most of the compositions showed densities close to that of PP homopolymer (Figure 6). From 20 to 40 wt. (\%) RHF it seems that a slight tendency of increasing density with increasing rice husk concentration occurred. However, this effect can be considered expressionless since addition of $40 \mathrm{wt}$. (\%) RHF increased density from 0.91 to $0.94 \mathrm{~g} . \mathrm{cm}^{-3}$, that means $3.3 \%$. Such behavior suggests that the polymer matrix was not able to penetrate into the RHF lumen and cell walls thus producing composites with interesting low densities. The addition of the coupling agent MAPP produced a slight increase in the density that could be explained by a higher compatibility among the filler and the polymer matrix thus diminishing the presence of voids in the material. However the effect of MAPP on the density was not very significant at all. The important conclusion is that these composites are very light materials that can be useful in applications that require low weight.

\subsection{Morphology}

The morphology of brittle-fractured surfaces was studied by means of scanning electron microscopy. The images of compos- 


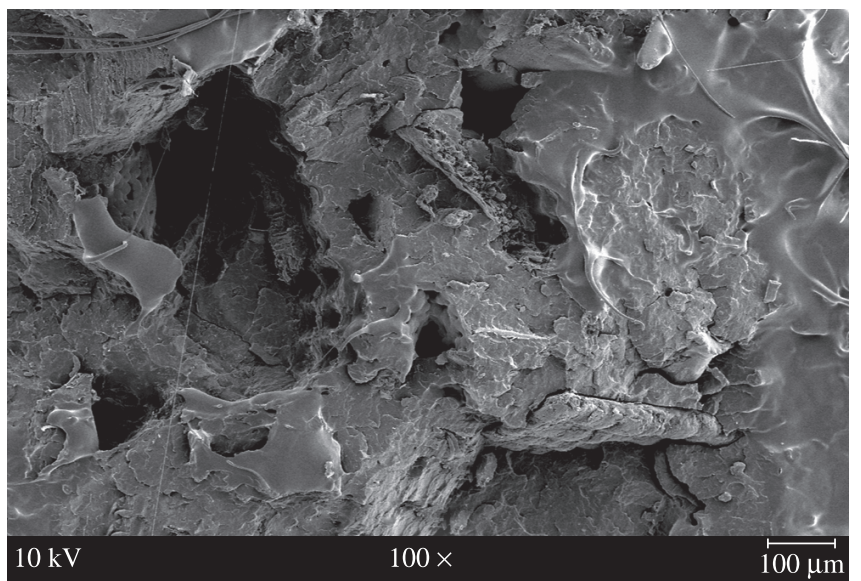

(a)

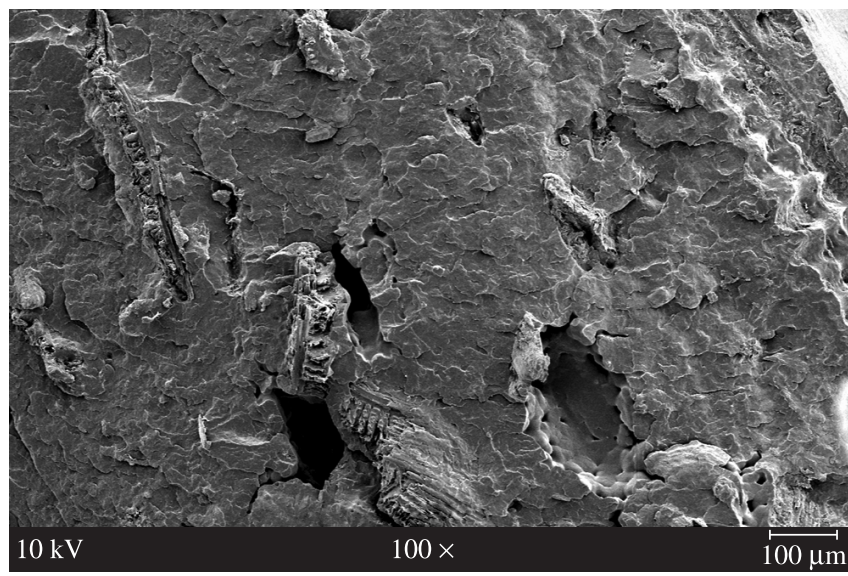

(b)

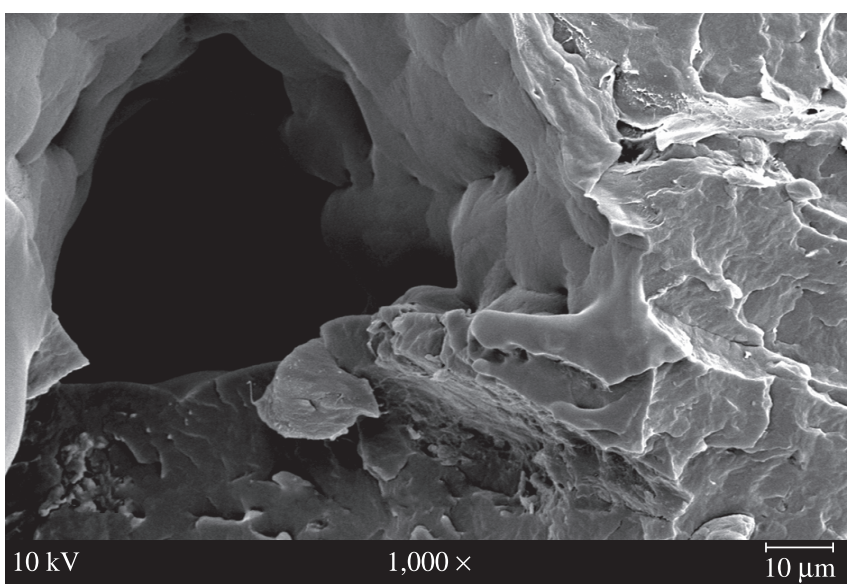

(a')

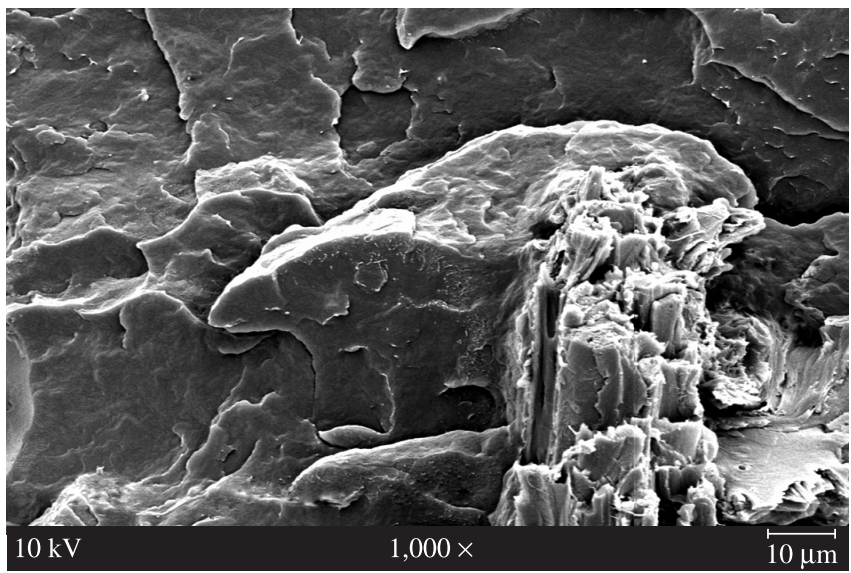

(b')

Figure 7. SEM micrographs of brittle-fractured surfaces of composites with 20 wt. (\%) RHF: a) without MAPP; b) with MAPP.

ites containing 20 wt. (\%) RHF, with and without added MAPP, are shown in Figure 7. The non-coupled composite displayed a rough morphology with the presence of voids between the filler particles and the polymer matrix, clearly indicating the poor interaction between them. From Figures $7 \mathrm{a}$ and $7 \mathrm{~b}$ it is possible to verify that the presence of MAPP reduced the voids sizes and turned the surface more homogeneous confirming its effect on promoting adhesion in the interfacial region. A closest look at the surfaces in the more magnified images shows that there are no free spaces between the particles and the continuous matrix that turns more difficult fiber pull-out during brittle fracture. The observed morphology confirms the explanations for the lower degree of water absorption and the higher density determined in composites containing MAPP.

\section{Conclusions}

Rice husk was milled and dried for using as filler in PP composites. It was verified that it is feasible to use this by-product of the rice milling process as a low cost filler, in view of the properties of the obtained products. The composite stiffness was seen to increase with increasing filler loading. The tensile strengths slightly decreased, however they were improved in the presence of the coupling agent MAPP. It was verified that MAPP/RHF ratio of 0.03 produced the best results. Higher ratios of the coupling agent showed poorer effect on tensile strength. Density determinations showed that PP/RHF composites are very light materials since its densities did not increase too much with respect to pure PP (maximum 3.3\% increasing for $40 \mathrm{wt}$. (\%) RHF). Addition of MAPP also reduced the degree of water absorption $(>20 \%)$, making these materials more suitable for using in damp environments. MAPP coupled composites showed more homogeneous morphology due to the better compatibility among the filler and the matrix. This result produced materials with lower void content that decreased the water absorption level with slight increase in the density of the composites.

\section{Acknowledgements}

The authors thank to BRASKEM and AM MEIREBE for raw materials supplying and toUFRGS and CAPES for supporting this research.

\section{References}

1. Nouri MR, Dogouri FJ, Oromiehie A and Langroudi AE. Mechanical properties and water absorption behaviour of chopped rice husk filled polypropylene composites. Iranian Polymer Journal. 2006; 15(9):757-766.

2. Premalal HGB, Ismail $\mathrm{H}$ and Baharin $\mathrm{A}$. Comparison of the mechanical properties of rice husk powder filled polypropylene composites with talc filled polypropylene composites. Polymer Testing. 2002; 21(7): 833-839. 
3. Silva RV and Aquino EMF. Curauá fiber: A new alternative to polymeric composites. Journal of Reinforced Plastics and Composites. 2008; 27(1):103-112.

4. Wang W, Sain M and Cooper PA. Study of moisture absorption in natural fiber plastic composites. Composites Science and Technology. 2006; 66(3-4):379-386.

5. Sanadi AR, Caulfield DF and Rowell RM. Reinforcing polypropylene with natural fibers. Plastics Engineering. 1994; 50(4):27-28.

6. Kim HS, Lee BH, Choi SW, Kim S and Kim HJ. The effect of types of maleic anhydride-grafted polypropylene (MAPP) on the interfacial adhesion properties of bio-flour-filled polypropylene composites. Composites Part A: Applied Science and Manufacturing. 2007; 38(6):1473 -1482.

7. Nachtigall SMB, Cerveira GS and Rosa SML. New polymeric-coupling agent for polypropylene/wood-flour composites. Polymer Testing. 2007; 26(5):619-628.

8. Piva AM, Steudner SH and Wiebeck H. Physico-mechanical properties of rice husk powder filled polypropylene composites with coupling agent study. In: Proceedings of the Fifth International Symposium on Natural Polymer and Composites; 2004; São Pedro/SP, Brazil.

9. Yang HS, Kim HJ, Son J, Park HJ, Lee BJ and Twang TS. Rice-husk flour filled polypropylene composites; mechanical and morphological studies. Composite Structures. 2004; 63(3-4):305-312.

10. Yang HS, Kim HJ, Park HJ, Lee BJ and Twang TS. Water absorption behavior and mechanical properties of lignocellulosic filler-polyolefin bio-composites. Composite Structures. 2006; 72(4):429-437.

11. Yang HS, Wolcott MP, Kim HS, Kim S and Kim HJ. Properties of lignocellulosic material filled polypropylene bio-composites made with different manufacturing processes. Polymer Testing. 2006; 25(5):668-676.

12. Kim HS, Kim S, Kim HJ and Yang HS. Thermal properties of bio-flourfilled polyolefin composites with different compatibilizing agent type and content. Thermochimica Acta. 2006; 451:181-188.

13. Kim HS, Lee BH, Choi SW, Kim S and Kim HJ. The effect of types of maleic anhydride-grafted polypropylene (MAPP) on the interfacial adhesion properties of bio-flour-filled polypropylene composites. Composites: Part A. 2007; 38(6):1473-1482.
14. Yang HS, Kim HJ, Park, HJ, Lee BJ and Hwang TS. Effect of compatibilizing agents on rice -husk flour reinforced polypropylene composites. Composite Structures. 2007; 77(1):45-55.

15. Rosa SML, Nachtigall SMB and Ferreira CA. Thermal and dynamicmechanical characterization of rice-husk filled polypropylene composites. Macromolecular Research. 2009; 17(1):8-13.

16. Martí-Ferrer F, Vilaplana F, Ribes-Greus A, Benedito-Borrás A and SanzBox C. Flour rice husk as filler in block copolymer polypropylene: Effect of different coupling agents. Journal of Applied Polymer Science. 2006; 99(4): 1823-1831.

17. Wang W, Sain M and Cooper PA. Study of moisture absorption in natural fiber plastic composites. Composites Science and Technology. 2006; 66(3-4):379-386.

18. Lee SY, Yang HS, Kim, HJ, Jeong, CS, Lim BS and Lee JN. Creep behavior and manufacturing parameters of wood flour filled polypropylene composites. Composite Structures. 2004; 65(3-4):459-469.

19. Ismail $\mathrm{H}$, Edyham MR and Wirjosentono B. Bamboo fibre filled natural rubber composites: the effects of filler loading and bonding agent. Polymer Testing. 2002; 21(2):139-144.

20. Danyadi L, Janecska T, Szabó Z, Nagy G, Móczó J and Pukánszky B. Wood flour filled PP composites: compatibilization and adhesion. Composites Science and Technology. 2007; 67(13):2838-2846.

21. Luz SM, Del Tio J, Rocha GJM, Gonçalves AR and Del'Arco Jr. AP. Cellulose and cellulignin from sugarcane bagasse reinforced polypropylene composites: Effect of acetylation on mechanical and thermal properties. Composites Part A - Applied Science and Manufacturing. 2008; 39(9):1362-1369.

22. Rana AK, Mandal BC, Mitra R, Jacobson R, Rowell A and Banerjee N. Short jute fiber reinforced polypropylene composites: Effect of compatibilizer. Journal of Applied Polymer Science. 1998; 69(2):329-338.

23. Bledzki AK, Letman M, Viksne A and Rence L. A comparison of compounding processes and wood type for wood fibre-PP composites. Composites Part A: Applied Science and Manufacturing. 2005; 36(6):789-797.

24. Prachayawarakorn J and Yaembunyng N. Effect of recycling on properties of rice husk-filled-polypropylene. Journal of Science and Technology. 2005; 27(2):343-352.

25. Shibata S, Cao Y and Fukumoto I. Lightweight laminate composites made from kenaf and polypropylene fibres. Polymer Testing. 2006; 25(2):142-148. 